and Mode of Action. / Ed. A.L. Fink, Y. Goto. New York, Basel, Hong-Kong.: Marcel Derrker Inc. - 1998. - P. $533-575$.

4. Ellis R.J., van der Vies S.M. Molecular chaperones. Annual Review of Biochemistry. - 1991. - Vol. 60. - P. $321-347$.

5. Gaestel M., Starke K. Molecular chaperones in health and disease. - Springer. - 2006. $-446 \mathrm{p}$.

6. Giese A., Kretzschmar H.A. Prion-induced neuronal damage - the mechanisms of neuronal destruction in the subacute spongiform encephalopathies. Curr. Top. Microbiol. Immunol. - 2001. - Vol. 253. - P. 203-217.

7. MacRae T. H. Structure and function of small heat shock a-crystallin proteins: established concepts and emerging ideas. Cell. Mol. Life Sci. - 2000. - Vol. 57. -

P. 899-913.

8. Netzer, W.J. and Hartl, F.U. Protein folding in the cytosol: Chaperonin-dependent and independent mechanisms. Trends Biochem Sci. - 1998. - Vol. 23. - P. 68-73.

9. $\quad$ Panasenko, O. O.; Seit Nebi, A.; Bukach, O. V.; Marston, S. B.Gusev, N. B. Structure and properties of avian small heat shock protein with molecular weight 25 kDa. Biochim Biophys Acta. - 2002. - Vol. 1601. - P. 64-74.

10. Prusiner S.B. Molecular biology of prion diseases. Science. - 1991. - Vol. 252. -

P. $1515-1522$.

11. Prusiner S.B. Biology and genetics of prion disease. Annual Review of Microbiol. Palo Alto (Calif.). - 1994. - Vol. 48. - P. 655-686.

12. Prusiner S.B. Prions. P. N. A. S. USA. - 1998. - Vol. 95, № 3. - P. 13363-13383.

13. Rybakov S.S. Scrapie and other animal and human prion diseases. - Vladimir. - 2003.- 200 p.

14. Soti C., Csermely P. Protein stress and stress proteins: implications in aging and disease. - Journal of Biosciences. - 2007. - V. 32 (3). - P. 511-515.

UDC 591.477+615.015.16+612.821+616-008.61:615.5+616-00.4-001.5 DOI 10.22448/AMJ.2017.3.52-53

\title{
STRUCTURAL CHANGES OF SKIN LIMBS OF LIMBS IN LOCAL COOLING ON THE BACKGROUND OF ANTIOXIDANT INTRODUCTION.
}

\author{
Malyuk EA, knikishina@mail.ru
}

\author{
Amur State Medical Academy, Blagoveshchensk, Russian Federation
}

Abstract The ambient temperature is one of the significant factors that affect the living organism. Man's mastery of Siberia, the northern territories and the southern subpolar, whose climatic features are low temperatures, draws special attention to questions about the possibilities, limits and mechanisms for adapting humans and animals to cold. In this case, there are some mechanisms of the damaging effect of the cold. This can be direct cryo damage, when a low temperature is used to conserve cells, cell suspensions and tissues. The following manifestation of the cold factor on the organism as a whole only at an ambient temperature below $\sim 30^{\circ} \mathrm{C}$ and at the same time, on open areas of the body may arise

Key words: skin, epidermis, dermis, cold, antioxidants

Most cells and organs are able to withstand acute ischemic hypoxia within 30-60 minutes without irreversible damage, but the sensitivity of different tissues to ischemia is not the same. In open areas of the body, frostbites may occur due to the damaging effect of cold directly on the tissue.

Local cooling is one of the most common environmental impacts that a person experiences from time to time, living in the northern regions of Siberia and the Far East.

Lipid peroxidation (LPO) of cell membranes is one of the types of normal metabolic process and proceeds continuously with lowefficiencyinalltissues of the body. Undertheaction oflowtemperatures, freeradicalsaccumulating incellsintheform of oxygensingletstotoxicconcentrationsleadtosecondarydamagetocellmembranestructures. Intheconnectivetissuethere aresignsofaninflammatoryreaction. Destructive processes developagainstabackground oftissuetemperature restoration.

Preparations of antioxidant action, in particular dihydroquercetin - the main flavanoid compound of larch wood of Siberia, has a wide spectrum of pharmacological effects, has antioxidant activity, which allows using it as cryoprotectant as a substance that prevents cellular edema.

Objective

The object of ourstudywastheskin material ofthelegs of ratssubjected tolocalfrostbite ofone of the hindlimbswith a cotton swab soaked in liquid nitrogen. For pharmacological correction, animals received dihydroquercetin orally at a dose of $2.5 \mathrm{mg}$ /100 g of weight for 7 days before the action of the cold factor and $2.5 \%$ of the ointment on a vaseline basis for 7 days similarly.

Materials and methods Methods of work were - histological - collection of material (macromicroscopic preparation), fixation, microtemporaing, staining: staining with hematoxylin and eosin, light microscopy of slices and analytical morphometry, stereological analysis, statistical processing of the data. 
Results and discussion In the control group (not receiving a pharmacological correction) that underwent local cooling and withdrawn from the experiment immediately after the cold exposure, the following morphological changes are observed in the pre-active period of the cold trauma: the boundaries between the layers of the epidermis and the cells themselves are stilted, the nuclei of the cells of the basal and granular layers are picotized, .e. phenomena of paranecrosis are observed. The dye stains the epidermis cells diffusely. The cytoplasm of epithelial cells is vacuolized. From the side of the vessels of the papillary layer of the dermis, stasis phenomena are observed, a persistent spasm of the dermis vessels is noted, which indicates the cold stress. Erythrocytes are glued together in "coin pillars" and capillaries are clogged, and the phenomena of occlusion of the microcirculatory system are visible.

With topical application of dihydroquercetin from the side of the epidermis, the peeling effect is observed, which indicates the keratolytic action of the dihydroquercetin preparation, the keratinization processes proceed without any peculiarities. From the side of the dermis, the edema of the middle degree of expression in the reticular layer is revealed, in addition, there is an increase in the fibroblastic reaction. Thus, one can judge the positive effect of the drug on water-electrolyte, protein metabolism in the skin and stimulating effect on the synthesis of glycosaminoglycans with topical application of dihydroquercetin. In the subgroup subjected to local cooling, against the backdrop of topical application of dihydroquercetin, and the inferior release from the experiment, compared with the control subgroup, less pronounced phenomena of paranecrosis are noted. From the side of the vessels of the papillary layer of the dermis, the phenomenon of stasis is manifested to a lesser degree, which indicates the cryoprotective action of dihydroquercetin in topical application.

With oral administration of dihydroquercetin in a subgroup subjected to local cooling, the phenomena of paranecrosis are less than in the control group. However, the cryoprotective effect for oral administration is less pronounced than with local use of the preparation, which indicates a rapid biotransformation of the drug for oral administration.

Thus, against the background of the use of dihydroquercetin, a visible cryoprotective effect is observed, which is most pronounced when applied locally, which indicates a rapid biotransformation of flavonoids by oral administration.

References:

1. Kotelnikov V.P. Frostbites. - M .: Medicine, 1988. -256c.

2. Myader OD, Adaskevich VP Morphofunctional dermatology - Moscow 2006 - P. 655-656.

3. Dorovskih V.A., Borodin E.A., Tseluyko S.S., The antioxidants in the prevention and korrektsii cold stress. - Blagoveshchensk: AGMA - 2001. -183 p.

4. Myadelets O.D., Adaskevich V.P., Morfofunktcionalnaja dermatology - Moscow 2006 - P. 655-656.

5. $\quad$ Nozdrin V.I., Barashkova S.A., Semchenko V.V. Leather and its derivatives - Omsk - Eagle - 2005 - 7-24.

6. Teselkin Y.O., Zhambalova B.A., Babenkova I.V. and others. The antioxidant properties of DHQ Tutorial "Biophysics" in 1996. T. 41, no. 3, pp 620 - 624.

7. Gnaiger E., Kuznetsov A. V., Rieger O., Amberger A., Fuchs A., Stadlmann S., Eberl T., Margreiter R. Mitochondrial defects by intracellular calcium overload versus endothelial coldischaemia/reperfuston injury // Transplant International. - 2000. - T. 13. N.7. - P. 555-557.

\section{DOI 10.22448/AMJ.2017.3.53-54 \\ CLINICAL APPLICATION STATUS ON ANTI-INFLAMMATORY OF TRADITIONAL CLASSICAL FORMULA-ZHIBAIDIHUANG PILL}

\section{Mingjiyang1, Dingyan1, Liyang1, Guoshuang1, Jiangxicheng*}

(1. Heilongjiang university of Chinese medicine, the Harbin city of heilongjiang province 150040;)

Abstract:Objective: To provide basis and reference data for the clinical application and pharmacological research onanti-inflammatory of Zhibai dihuang pill. Methods: The data and information from related literature prove the clinical effect of Zhibai dihuang pill, including research thought, method and progress . Introducing the ideas, methods and progress of clinical effect on Zhibai dihuang pill. Results: This paper summarizes the research progress of the Zhibai dihuang pill's effect on anti-inflammatory. Conclusion: the zhibai dihuang pill could cure various diseases caused by fire excess from yin deficiency, and adjust the level of the index factors associated with disease.

keywords : the zhibai dihuang pill, Clinical application

Zhibaidihuang pill consiste of Anemarrhena, phellodendron, Radix Rehmanniae Preparata, Fructus Corni, peony bark, Chinese yam, Poria, Alisma, it could cure treatment of hyperactivity of fire due to yin deficiency, such as hot flashes sweating, dry mouth and sore throat, tinnitus, spermatorrhea, short red urine and other symptoms. zhibaidihuang pill has anti-inflammatory effect, including Senile vaginitis, periodontitis, gingivitis, nephritis and so on. It summarized as follows.

1 Senile vaginitis Zhibaidihuang Pill vaginitis has obvious effect mainly for senile on treatment of vaginitis. Senlian Ruan[1] studied the clinical effect of Zhibaidihuang pill in treatment of senile vaginitis. She studied in 120 patients with senile vaginitis, and divided them randomly into observation group and control group, which has 60 patients in each group. The Patients in the control group was treated with Metronidazole Tablets and the patients in the observation group were treated with Zhibaidihuang pill. Comparing the therapeutic effects of two groups, we find that the 